\title{
Divergent Synthesis of Indolenine and Indoline Ring Systems by Palladium-Catalyzed Asymmetric Dearomatization of Indoles
}

\author{
Dong Gao and Prof. Dr. Lei Jiao*
}

\begin{abstract}
Dearomatized indole derivatives bearing a C3- or C2stereocenter exist ubiquitously in natural products and biologically active molecules. Despite remarkable advances in their synthesis, stereoselective and regio-divergent methods are still in a high demand Herein, a Pd-catalyzed intermolecular asymmetric spiroannulation of 2,3-disubstituted indoles with internal alkynes has been developed for the efficient construction of indoline structures with a C2-quaternary stereocenter. Stereospecific aza-semipinacol rearrangement of these indoline derivatives under acidic conditions afforded indolenine products bearing a C3-quaternary stereocenter, where the migrating group could be controlled by the reaction sequence. The asymmetric spiroannulation together with the subsequent aza-semipinacol rearrangement enabled a divergent access to dearomatized indole derivatives with either a C3- or a C2-quaternary stereocenter.
\end{abstract}

Indolenines bearing a C3-quaternary stereocenter and indolines bearing a C2-quaternary stereocenter are widely occurring core structures in many natural products and biologically active molecules,,$^{[1,2 b, 2 \mathrm{~d}]}$ and the synthetic methods that enable efficient construction of these core structures is highly demanded ${ }^{[2]}$ Catalytic asymmetric dearomatization (CADA) reactions serve as one of the most straightforward approach to chiral building blocks from aromatic substrates. ${ }^{[3]}$ Recently, a series of CADA reactions have been developed for the construction of chiral indolenine/indoline derivatives based on the reactivity of $\mathrm{C}\left(\mathrm{sp}^{2}\right)$-Pd species (Scheme 1$){ }^{[4-6]}$ The majority of these reactions were performed in an intramoleculcar manner (Scheme 1a), in which a haloarene or an acetylene is tethered to the N1-, C2- or C3position of indole as the $\mathrm{C}\left(\mathrm{sp}^{2}\right)$-Pd precursor. The You group achieved enantioselective $\mathrm{C} 3$-arylation of $\mathrm{C} 3$-tethered indoles:; ${ }^{[4 \mathrm{p}]} \mathrm{Jia}^{[4 \mathrm{~b}, 4 \mathrm{k}]}$ and Fukuyama $^{[4 n]}$ developed the dearomative Heck reaction of N1- and C2-

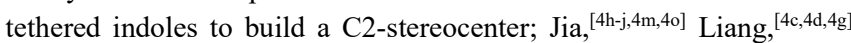
Lautens, ${ }^{[4 \mathrm{~h}]}$ and $\mathrm{Dai}^{[4 \mathrm{e}]}$ reported the asymmetric dearomative difunctionalization of $\mathrm{C} 2$-tethered indoles by employing an external nucleophile.

Compared with intramolecular cyclization, the intermolecular version allows for a more divergent approach to dearomatized products. In this regard, Zhang and co-workers reported recently an enantioselective annulative dearomatization of C3-bromoarylindoles with alkynes using the $\mathrm{Pd} / \mathrm{Sadphos}$ catalytic system to access various spiro-indolenines with a C3-quaternary stereocenter (Scheme 1b). ${ }^{[5]}$ However, to date the intermolecular asymmetric dearomatization of $\mathrm{C} 2$-arylindoles has not been reported yet, and stereoselective construction of structurally diversified indoline/indolenine derivatives remains a formidable challenge. ${ }^{[7]}$

Herein, we report a Pd-catalyzed asymmetric intermolecular spiroannulation reaction of $\mathrm{C} 2$-arylindoles with internal alkynes, leading

[*] D. Gao, Prof. Dr. L. Jiao

Center of Basic Molecular Science (CBMS), Department of

Chemistry, Tsinghua University, Beijing 100084, China

E-mail: Leijiao@mail.tsinghua.edu.cn

Supporting information for this article is given via a link at the end of the document. to the formation of spiro-indolines bearing a C2-quaternary stereocenter (Scheme 1c). These products could undergo a stereospecific azasemipinacol rearrangement under acidic conditions, affording fusedindolenines with a C3-quaternary stereocenter. Furthermore, the migration selectivity of this process could be tuned by the selection of reaction sequence. The asymmetric spiroannulation together with the stereospecific rearrangement enabled a divergent access to dearomatized indole derivatives with either a $\mathrm{C} 3$ - or a $\mathrm{C} 2$-quaternary stereocenter.

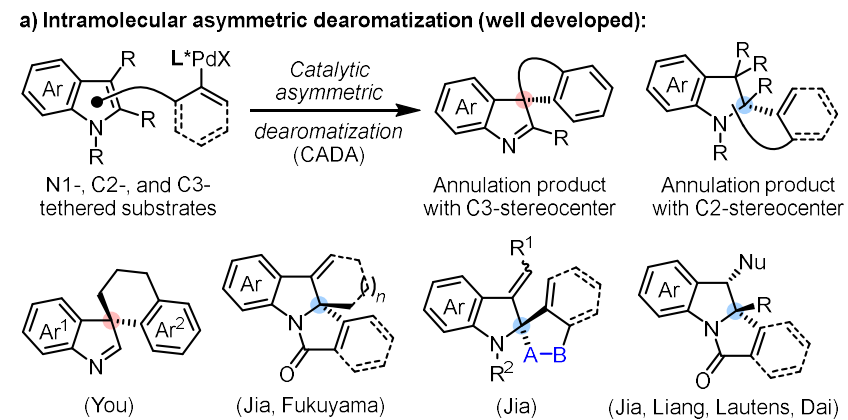

b) Intermolecular asymmetric dearomatization (less developed):

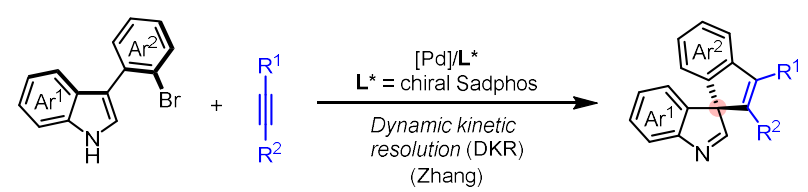

c) Intermolecular DKR of 2,3-disubstituted indoles (this work):

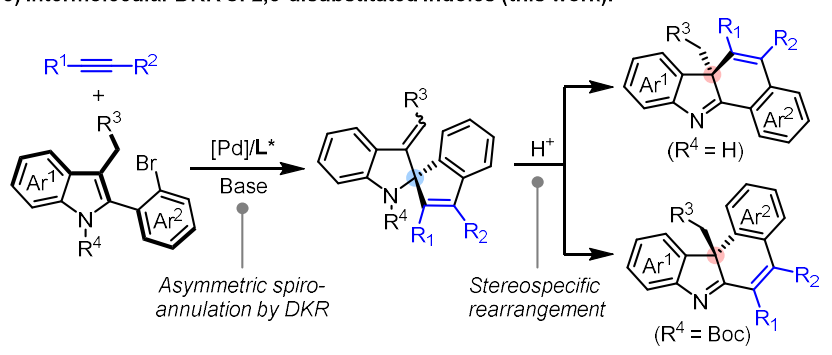

Scheme 1. Palladium-Catalyzed Asymmetric Dearomatization of Indoles Involving a $\mathrm{C}\left(\mathrm{sp}^{2}\right)-\mathrm{Pd}$ Species.

At the outset, we envisioned to attempt the reaction between Bocprotected 2-(2-bromophenyl)-3-methyl-1 $H$-indole (1a) and alkynes as a model reaction. We first focused on the aryl-aryl rotational barrier of $\mathbf{1 a}$, since similar substrates exhibit axial chirality ${ }^{[5,6 \mathrm{~d}]}$ and facile interconversion between the two enantiomers is crucial for efficient dynamic kinetic resolution (DKR). ${ }^{[8]} \mathrm{We}$ found that, the enantiomers of 1a could be well resolved by chiral HPLC, indicating that they interconvert slowly under room temperature (Scheme 2). The separation of both enantiomers allowed us to determine the kinetic parameters of the racemization process by performing the reaction under elevated temperatures. ${ }^{[9]}$ On the basis of the measured enantiomerization rate constants, the enantiomerization barrier of $1 \mathbf{a}$ was determined to be 25.4 $\mathrm{kcal} / \mathrm{mol}$ at $298 \mathrm{~K}$ by applying the Erying equation, which ensures a rapid racemization process at elevated temperature. 

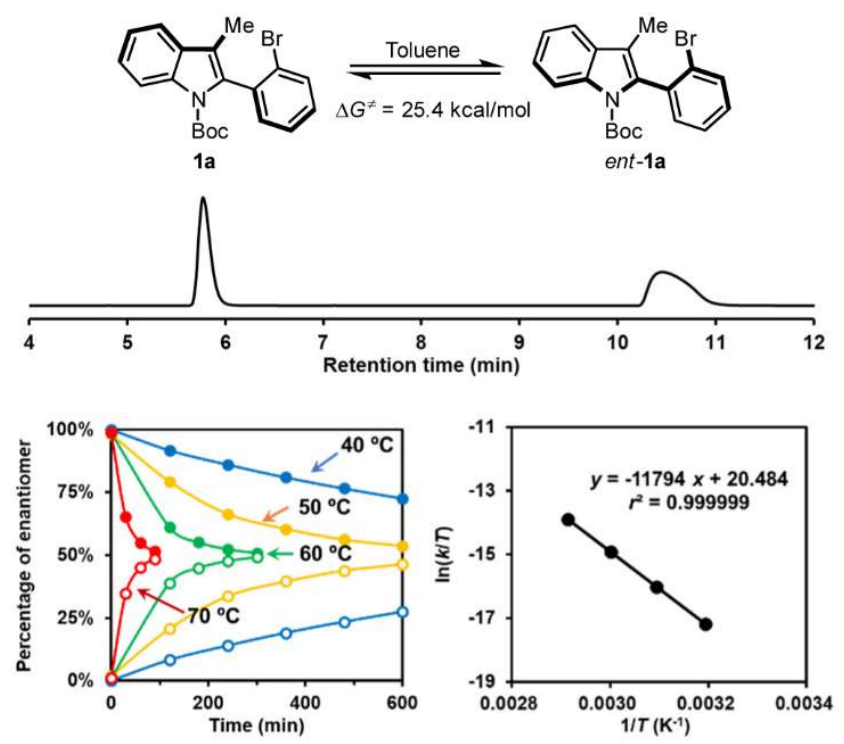

Scheme 2. Rotational Barrier Determination for Substrate 1a

Bearing this information in mind, we commenced the study on the reaction between 1a and diphenylacetylene (2a) by employing $\operatorname{Pd}(\mathrm{dba})_{2}$ as the precatalyst and toluene as the solvent (Table 1). It was found that, chiral NHC ligand L1, BINAP (L2), spiro-phosphoramidite ligand L3, and Feringa-type ligand $\mathbf{L} \mathbf{4}$ resulted in unsatisfactory results (entries 14). To our delight, a promising result was observed by employing the Carreira ligand $\mathbf{L 5}$ with $t$-BuOLi as the base at $120^{\circ} \mathrm{C}$, affording product 3aa in 55\% NMR yield with 92:8 er (entry 5). A better result was achieved by lowering the reaction temperature to $90{ }^{\circ} \mathrm{C}$ and switching the base to $\mathrm{MeOLi}$, providing 3aa in $88 \%$ isolated yield with $95: 5$ er (entry 9). Further optimization on ligand structure indicated that more sterically hindered ligands $\mathbf{L 6}$ and $\mathbf{L} 7$ exhibited a negative effect on enantioselectivity (entries 10-11). The fluoro-substituted ligand $\mathbf{L 8}$ was found to give comparable yield and slightly inferior enantioselectivity (entry 12). A comparison showed that phosphoramidite ligand $\mathbf{L 9}$ was inferior compared with $\mathbf{L 5}$ (entry 13). A brief screen of the $N$-protecting group on indole indicated that the Boc group was the best amongst tosyl, acetyl, and methyl group (entries 14-16).

To illustrate the generality of the reaction, the scope of the indole coupling partners was initially investigated (Table 2). Gratifyingly, 2aryl-3-methylindole substrates with fluoro, chloro, methoxyl, and methyl substituents (1b-e) at the 5-position of the phenyl ring worked well under the optimal reaction conditions, giving the corresponding spiro-indoline products $\mathbf{3 b a - 3 e a}$ in $70-86 \%$ yield with 90:10 to $96: 4 \mathrm{er}$. Substrate bearing an electron-withdrawing trifluoromethyl group (1f) was also tolerated to afford $\mathbf{3 f a}$ in 92:8 er, whereas the reaction yield decreased to $23 \%$. 6-Methyl and 4,5-methylenedioxy substituent on the phenyl ring (1g-h) and a more sterically congested naphthyl group in place of the phenyl group (1i) were tolerated to provide the desired products 3ga-3ia in 39-99\% yield with 93:7-95:5 er. However, introduction of a methyl group at the 6-position $(\mathbf{1} \mathbf{j})$ of the phenyl moiety resulted in decreased enantioselectivity. Substituents on the indole moiety (5'-methyl, 5'-trifluoromethyl, 5'-chloro, and 4'-chloro) of the substrates (1k-n) were compatible with the reaction, delivering 3ka-3na in $33-82 \%$ yield with $93: 7-95: 5$ er, while the 7'-fluoro substituent significantly decreased the yield of the desired product 3oa. The use of 2-aryl-3-ethylindole substrate 1p led to a good yield of spiroannulation product 3 pa as a $\mathrm{C}=\mathrm{C}$ bond geometrical isomer mixture with diminished enantioselectivity.

Table 1. Optimization of the reaction conditions.

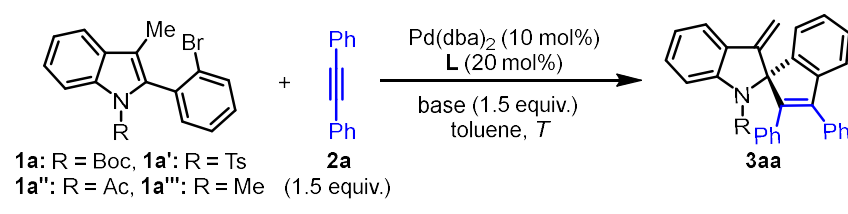

\begin{tabular}{|c|c|c|c|c|c|c|}
\hline Entry & Sub & Base & $\mathbf{L}$ & $T /^{\circ} \mathrm{C}$ & Yield(\%) $)^{[\mathrm{a}]}$ & $\mathrm{Er}^{[\mathrm{b}]}$ \\
\hline $1^{[\mathrm{c}]}$ & $1 a$ & $t$-BuONa & L1 & 120 & 9 & $53.5: 46.5$ \\
\hline $2^{[\mathrm{d}]}$ & $1 \mathrm{a}$ & $\mathrm{Cs}_{2} \mathrm{CO}_{3}$ & L1 & 120 & 23 & $51.5: 48.5$ \\
\hline $2^{[\mathrm{e}]}$ & $1 \mathrm{a}$ & $\mathrm{Cs}_{2} \mathrm{CO}_{3}$ & $\mathbf{L 2}$ & 120 & 0 & - \\
\hline $3^{[\mathrm{f}]}$ & $1 \mathrm{a}$ & $t$-BuOLi & $\mathbf{L 3}$ & 120 & 75 & $54: 46$ \\
\hline $4^{[\mathrm{g}]}$ & $1 \mathrm{a}$ & $t$-BuOLi & L4 & 120 & 12 & $75.5: 24.5$ \\
\hline 5 & $1 \mathrm{a}$ & $t$-BuOLi & $\mathbf{L 5}$ & 120 & 55 & $92: 8$ \\
\hline 6 & $1 \mathrm{a}$ & $i$-PrOLi & L5 & 120 & 60 & $92: 8$ \\
\hline 7 & $1 \mathrm{a}$ & MeOLi & L5 & 120 & 65 & $93: 8$ \\
\hline $8^{[\mathrm{h}]}$ & $1 \mathrm{a}$ & MeOLi & L5 & 100 & 70 & $95: 5$ \\
\hline $9^{[\mathrm{i}]}$ & $1 \mathrm{a}$ & $\mathrm{MeOLi}$ & L5 & 90 & 88 & $95: 5$ \\
\hline 10 & $1 \mathrm{a}$ & MeOLi & L6 & 95 & 52 & $44: 56$ \\
\hline 11 & $1 \mathrm{a}$ & MeOLi & L7 & 95 & 20 & $46: 54$ \\
\hline $12^{[\mathrm{i}]}$ & $1 \mathrm{a}$ & MeOLi & L8 & 90 & 89 & $92: 8$ \\
\hline $13^{[\mathrm{g}]}$ & $1 \mathrm{a}$ & $t$-BuOLi & L9 & 120 & 52 & $54.5: 45.5$ \\
\hline 14 & 1a' & MeOLi & L5 & 90 & $36^{[\mathrm{i}]}$ & $62: 38$ \\
\hline 15 & $1 \mathrm{a} "$ & MeOLi & L5 & 90 & n.d. ${ }^{[j]}$ & - \\
\hline 16 & 1a"” & MeOLi & L5 & 90 & n.d. ${ }^{[j]}$ & - \\
\hline
\end{tabular}

[a] Determined by ${ }^{1} \mathrm{H}$ NMR with $\mathrm{CH}_{2} \mathrm{Br}_{2}(0.1 \mathrm{mmol})$ as an internal standard. [b] Enantiomeric ratios were determined by chiral stationary phase HPLC.The absolute configuration of 3aa was confirmed by the single crystal X-ray diffraction analysis. [c] Using $\mathrm{Pd}(\mathrm{OAc})_{2}(10 \mathrm{~mol} \%)$ as palladium source, $\mathrm{KI}(1.5$ equiv) as additive, and Dioxane $(0.1 \mathrm{M})$ as the solvent. [d] Using $\left[\mathrm{Pd}\left(\mathrm{C}_{3} \mathrm{H}_{5}\right) \mathrm{Cl}\right]_{2}$ ( $5 \mathrm{~mol} \%$ ) as palladium source, $\mathbf{L} 1(15 \mathrm{~mol} \%)$, and Dioxane $(0.1 \mathrm{M})$ as the solvent. [e] Using $\left[\mathrm{Pd}\left(\mathrm{C}_{3} \mathrm{H}_{5}\right) \mathrm{Cl}\right]_{2}(2.5 \mathrm{~mol} \%)$ and L2 (7.5 mol\%). [f] Using Pd(dba) $)_{2}(5.0$ $\mathrm{mol} \%)$ and L3 (7.5 mol\%). [g] Using Pd(dba) 2 (10.0 mol\%) and L4 (15.0 mol\%). [h] $\mathrm{MeOH}$ (1.0 equiv.) as additive. [i] Yield of isolated product. [j] Not detected.

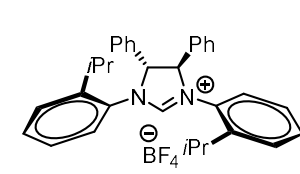

L1

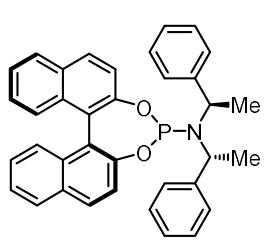

L4

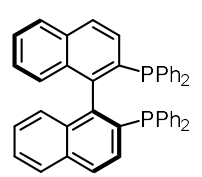

L2

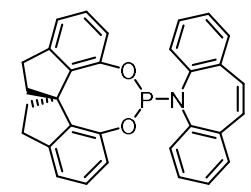<smiles>[R]c1ccc2c(c1)C=Cc1cc([R6])ccc1N2P(Oc1ccc2ccccc2c1-c1c(OP(Oc2cccc3ccccc23)N2c3ccccc3CCc3ccccc32)ccc2ccccc12)Oc1c([R])cc2ccccc2c1-c1c([R])cc2ccccc2c1[R]</smiles>

L9

L5: $\mathrm{R}_{1}=\mathrm{R}_{2}=\mathrm{H}$

L6: $R_{1}=M e \cdot R_{2}=H$

L7: $R_{1}=P h, R_{2}=H$

L8: $R_{1}=H \cdot R_{2}=F$ 
Table 2. Scope of indole substrates and internal alkynes ${ }^{[a]}$

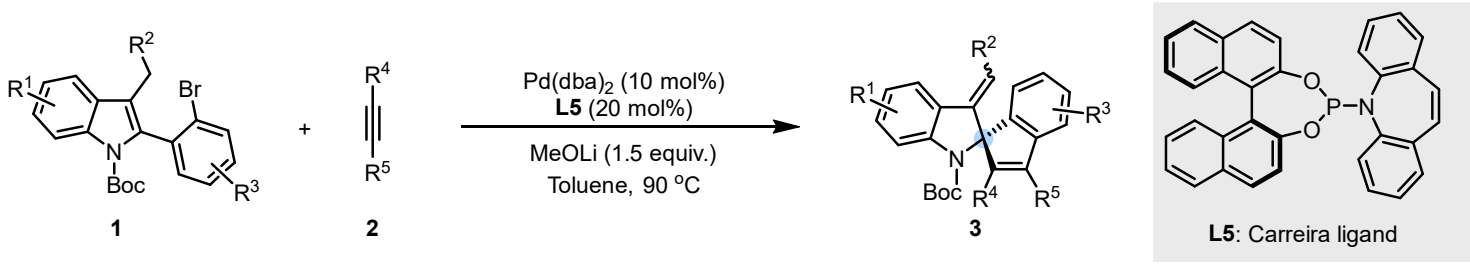

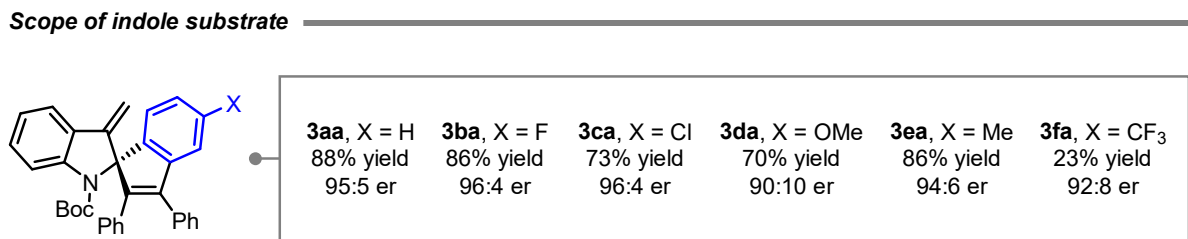

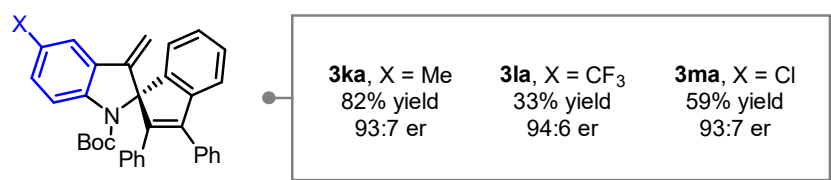
$62 \%$ yield, $76: 24$ er

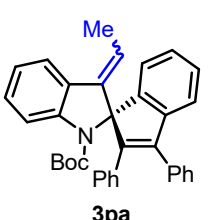

$79 \%$ yield, $Z / E=1: 2$ (Z)-3pa: $67.5: 32.5 \mathrm{er}$ (E)-3pa: 75.5:24.5 er

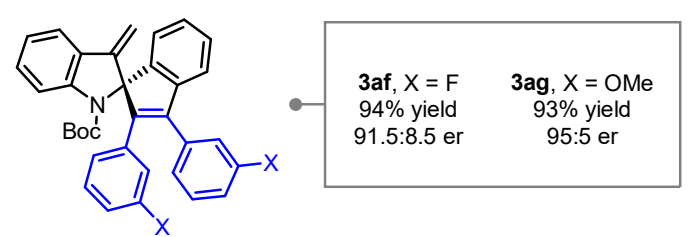

3ak

$91 \%$ yield, $92: 8$ er

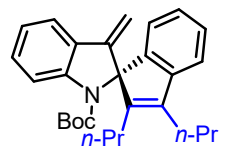
[98\%, $90: 10$ er on $1.3 \mathrm{~g}$ scale]

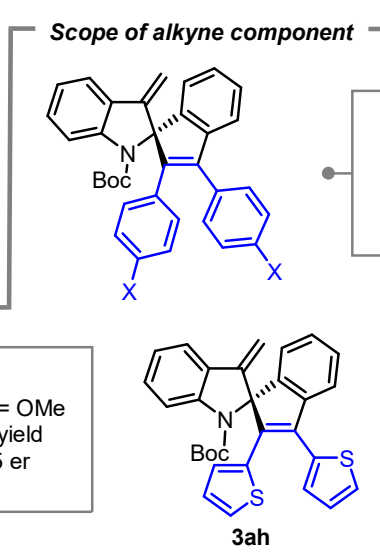

$16 \%$ yield, $91: 9$ er

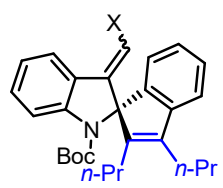

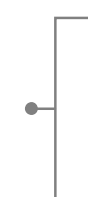
3pk, $\mathrm{X}=\mathrm{Me}$
$95 \%$ yield, $Z / E=1: 12$
(Z)-3pk: $90: 10$ er

(E)-3pk: 88:12 er

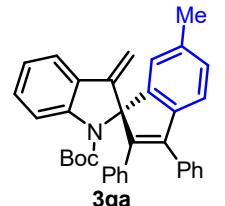

$87 \%$ yield, $95: 5$ er

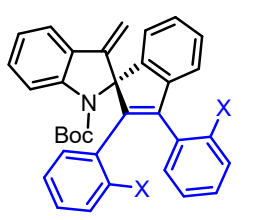

3ai, $X=F \quad 3 a j, X=M e$ $46 \%$ yield $0 \%$ yield 77:23 er

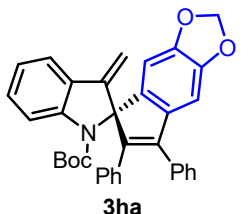

99\% yield, 95:5 er

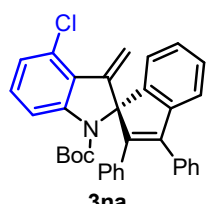

$64 \%$ yield, $95: 5$ er

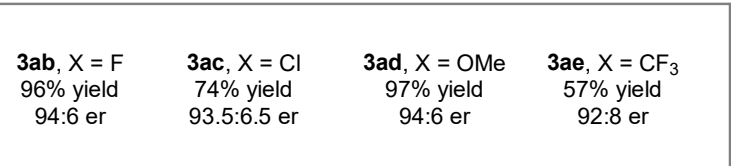

$3 q k, X=\mathrm{CO}_{2}{ }^{t} \mathrm{Bu}$

$55 \%$ yield, $Z / E=1: 12$

(Z)-3qk: 83:17 er

(E)-3qk: 88:12 er
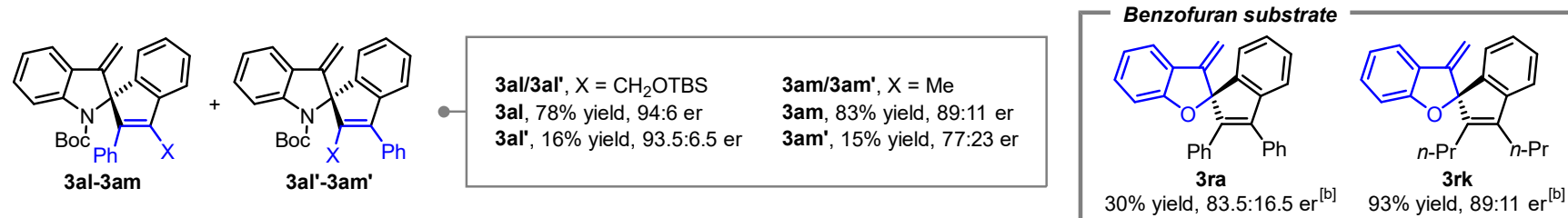

[a] Reaction conditions: 1 (1.0 equiv), 2 (1.5 equiv), and toluene $(0.1 \mathrm{M})$ under Ar. Yields of isolated products are reported. The Z/E ratios were determined by crude ${ }^{1} \mathrm{H}$ NMR. The er values were determined by chiral HPLC. [b] L4 (20 mol\%) was used in place of L5.

Then the scope of the internal alkyne was explored (Table 2). Symmetrical diaryl acetylenes with various substituents at the para- (2be) or meta- (2f-g) position of both phenyl rings participated in the reaction smoothly to give the corresponding products 3ab-3ag in 5797\% yield with 92:8-95:5 er. Di(thiophen-2-yl)acetylene (2h) could undergo the reaction with 1a, but afforded a low yield of cyclization product 3ah in 91:9 er. The ortho-substituent on the aryl groups of diarylacetylene generally exhibited a negative effect on the reaction: ortho-fluoro substituted 1,2-bis(2-fluorophenyl)ethyne $\mathbf{2 i}$ afforded product 3ai in a moderate yield with a low enantioselectivity (77:23 er), and no desired product was observed for the more sterically hindered ortho-methyl substituted diphenylacetylene $\mathbf{2} \mathbf{j}$. To our delight, the symmetrical dipropylacetylene $\mathbf{2 k}$ was found to be suitable to undergo the annulation with substrates 1a, 1p, and 1q. Notably, a gram-scale synthesis of 3ak $(1.31 \mathrm{~g})$ was carried out to afford the product in $98 \%$ yield with 90:10 er, indicating the scalability of the present method Moreover, the reactions of 2-aryl-3-ethylindole substrate 1p and 2-aryl3-tert-butoxycarbonylmethylindole substrate $\mathbf{1 q}$ with alkyne $\mathbf{2 k}$ 
afforded the corresponding products 3pk and 3qk in good yields and enantioselectivities. Finally, the unsymmetrical alkyl/aryl mixed acetylenes $\mathbf{2} \mathbf{I}$ and $\mathbf{2} \mathbf{m}$ produced cyclization products in good yields with decent enantioselectivities and satisfactory regioselectivities.

Interestingly, we found that the present protocol could be extended to a 2-aryl-3-methylbenzofuran substrate by employing $\mathbf{L} \mathbf{4}$ as the ligand, affording spiro[benzofuran-cyclopentane] 3ra and 3rk in comparable enantioselectivities.

The C2-spiroindoline structure in the cyclized products enabled a potential aza-semipinacol rearrangement ${ }^{[4 f, 10]}$ leading to the formation of a C3-stereocenter, and if the rearrangement proceeded stereospeficially, enantioenriched $\mathrm{C} 3$-substituted indolenine derivative could be obtained. Therefore, we attempted to perform an acid-promoted aza-semipinacol rearrangement on the spiroindoline products (Table 3). We found that, by treating the C3-methylene (3aa, 3aj, 3am) or C3ethylidene (3pj) substituted spiro-indolines with TFA (Condition A), the rearranged products bearing a C3-quaternary stereocenter (4aa, 4aj, 4am, and 4pj) were obtained in moderate to excellent overall yield without loss of enantiopurities. In this process both the cleavage of the $\mathrm{N}$-Boc group and the stereospecific rearrangement of the C2-substituent proceeded smoothly, and the aryl migration was favored over the alkenyl migration.

To figure out whether the rearrangement step occurs prior to or after the elimination of the $\mathrm{N}$-Boc group, we investigated another reaction sequence involving stepwise deprotection and rearrangement for the same set of $\mathrm{C} 2$-spiroindoline derivatives (Condition B). The deprotection of $\mathrm{N}$-Boc group proceeded smoothly by treatment with TMSOTf/2,6-lutidine, and the crude deprotected product was treated with TFA as before. To our surprise, this reaction sequence delivered alkenyl migration product (4aa', 4aj', 4am', 4pj') as the major product with complete retention of enantiopurities. This result indicates that the nature of the $N$-substituent has a remarkable effect on the azasemipinacol rearrangement, and under Condition A the rearrangement occurred prior to deprotection. Therefore, by choosing an appropriate reaction sequence, rearrange of $\mathrm{C} 2$-spiroindoline to $\mathrm{C} 3$-substituted indolenine with selective aryl/alkenyl migration could be achieved.

In order to gain more mechanistic insights into the Pd-catalyzed cascade spiroannulation and the regio-divergent aza-semipinacol rearrangement, we performed a DFT computational study (Scheme 3). The reaction between indole 1a and alkyne $\mathbf{1 b}$ catalyzed by $\mathrm{Pd} / \mathbf{L} 5$ was selected as the model, and the calculated reaction pathway is shown in Scheme 3a. It was found that, the reaction starts with the Pd-ligand complex, $\operatorname{Pd}(\mathbf{L 5})_{2},{ }^{[11]}$ and proceeds through oxidative addition, alkyne coordination and insertion, indole insertion, and $\beta$ - $\mathrm{H}$ elimination steps. The alkyne insertion step via TS2 turned out to be both turnover-limiting and selectivity-determining, and the overall activation barrier for the formation of 3aa was $20.4 \mathrm{kcal} / \mathrm{mol}$ in terms of Gibbs free energy. The other pathway leading to ent-3aa starts from the coordination of ent-1a with the Pd catalyst, and the key alkyne insertion step via TS2' was less favored by $1.1 \mathrm{kcal} / \mathrm{mol}$ compared with TS2, in agreement with the preference for $(R)$-product observed experimentally. It is notable that the barrier for the interconversion of atropisomers of 1a $\left(\Delta G^{\ddagger}=25.4\right.$ $\mathrm{kcal} / \mathrm{mol}$ ) seemed to be higher than that for the catalytic dearomatization via TS2 $\left(\Delta G^{\ddagger}=20.4 \mathrm{kcal} / \mathrm{mol}\right)$. Given that TS2 involves three components (catalyst, substrate 1a, and alkyne 2a at $0.01 \mathrm{M}, 0.1 \mathrm{M}$, and $0.15 \mathrm{M}$, respectively), the corrected barrier for the dearomatization reaction $\left(\Delta G^{\neq}=25.6 \mathrm{kcal} / \mathrm{mol}\right)$ fits the requirement for DKR. The fact that unconsumed 1a was determined to be racemic at different conversions confirmed the DKR scenario experimentally (see the Supporting Information for details).

Table 3. Aza-semipinacol rearrangement ${ }^{[a]}$
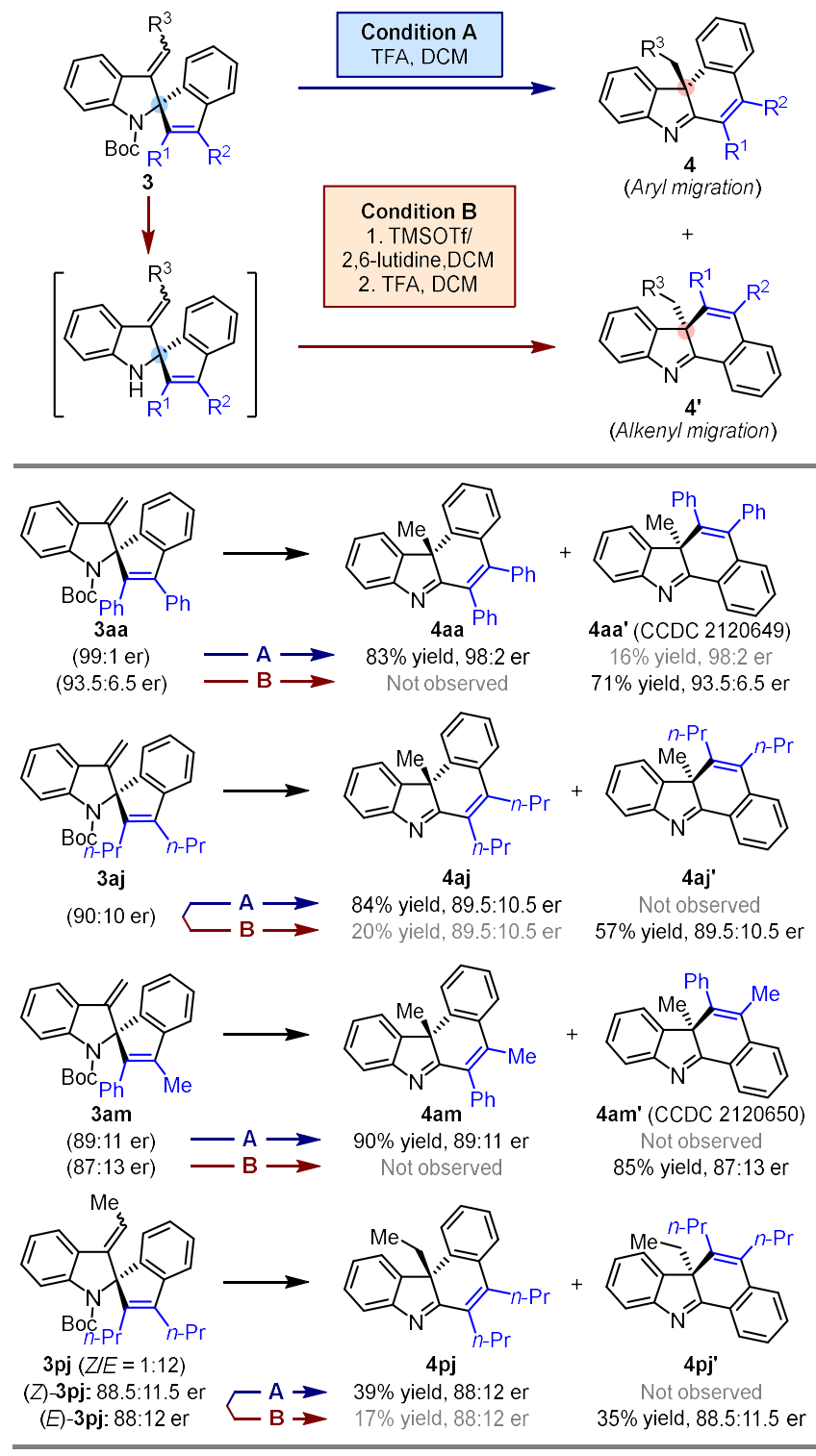

[a] Condition A: TFA/DCM = (1:10 v/v) (0.1 M). Condition B: 1. TMSOTf (4.0 equiv), 2,6-lutidine (5.0 equiv), DCM $(0.1 \mathrm{M}) 2$. TFA/DCM $=(1: 10 \mathrm{v} / \mathrm{v})(0.1 \mathrm{M})$ Yields of isolated product are reported. The ervalues were determined by chiral HPLC. TFA = trifluoroacetic acid, TMSOTf = trimethylsilyl trifluoromethanesulphonate. 
a) Mechanism of the asymmetric dearomatization reaction:
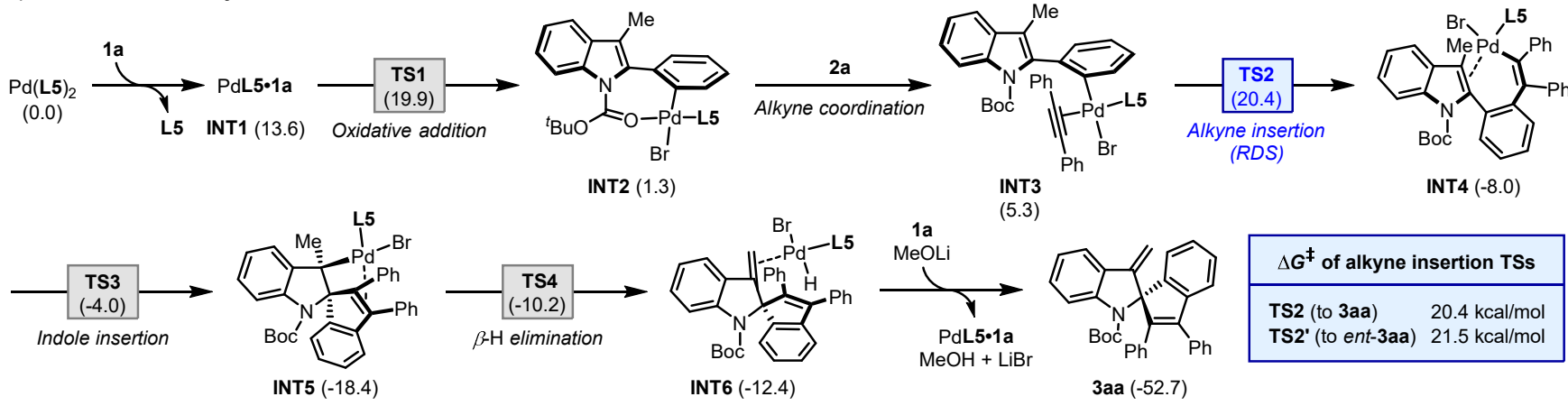

b) Mechanism of the aza-semipinacol rearrangment:

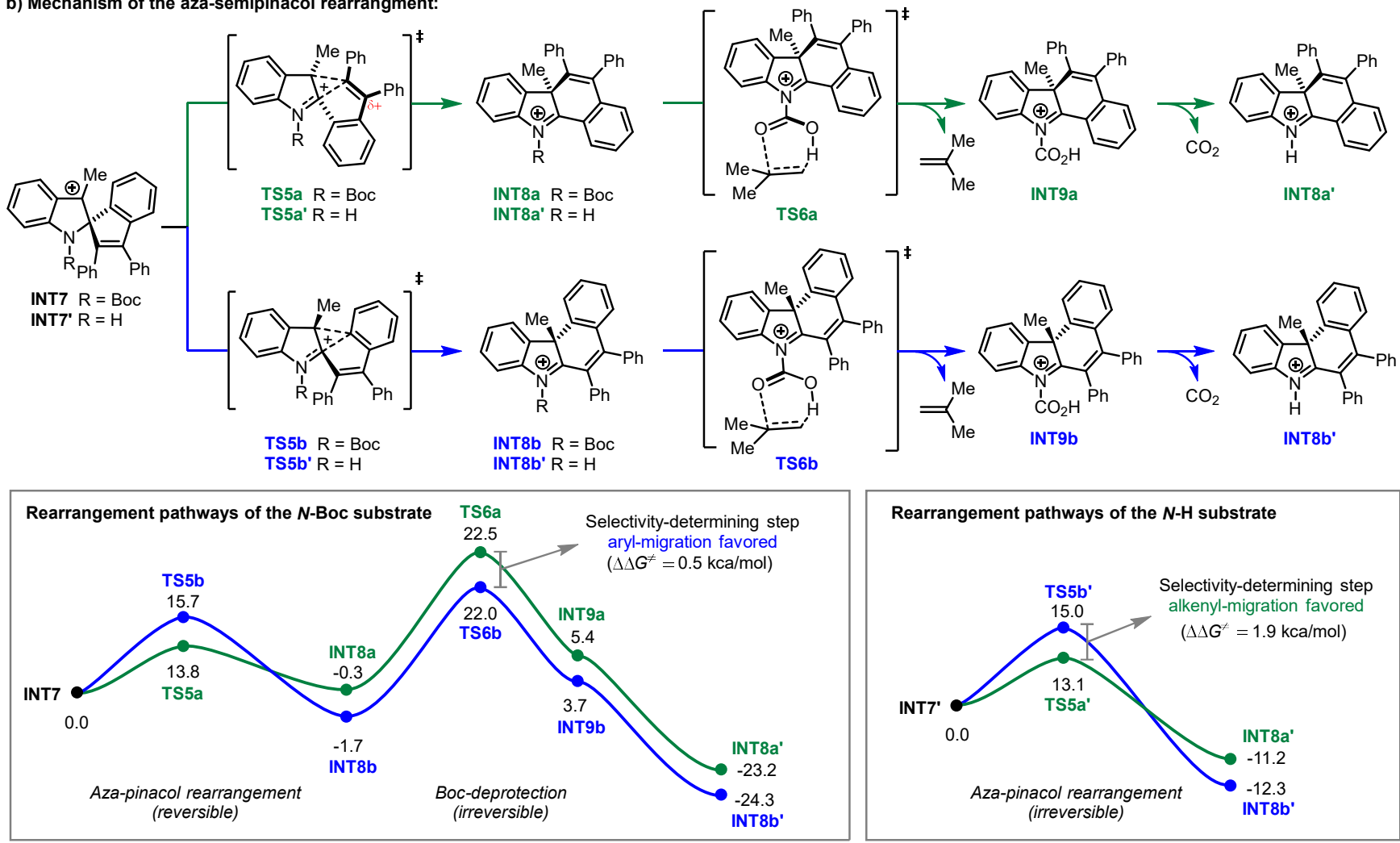

Scheme 3. DFT Computational Study on the Reaction Mechanism. Calculated Gibbs free energies in solution (in kcal/mol) are provided.

The aza-semipinacol rearrangement was also investigated by DFT calculation to understand the nature of the migration selectivity, employing the transformation of 3aa to $\mathbf{4 a a}$ and $\mathbf{4} \mathbf{a a}$ ' as the model (Scheme $3 \mathrm{~b}$ ). The result indicated the aza-semipinacol rearrangement of both the $N$-Boc substrate (starting from INT7) and the $N$-H substrate (starting from INT7') favors alkenyl migration (TS5a vs TS5b and TS5a' vs TS5b'). We attribute this trend to the fact that alkenyl migration transition states TS5a and TS5a' could better stabilize the positive charge due to the existence of the aryl rings, whereas this stabilizing effect lacks in the aryl migration transition states TS5b and TS5b'. Interestingly, for the $N$-Boc substrate the rearrangement is reversible due to a more energy-demanding Boc-deprotection step, while for the $\mathrm{N}-\mathrm{H}$ substrate the rearrangement is irreversible and thus determines the migration selectivity. As a result, the migration selectivity of the $N$-Boc substrate is dictated by the Boc-deprotection step via TS6a and TS6b, and the preference for the aryl-migrated product in this step inherits from the thermodynamic stability of the rearranged intermediates INT8a and INT8b.
In summary, we have developed a palladium-catalyzed enantioselective intermolecular dearomatization of $\mathrm{C} 2$-arylindoles with internal alkynes, leading to $\mathrm{C} 2$-spiroindolines bearing a $\mathrm{C} 2$-quaternary stereocenter with good yields and enantioselectivities. The stereospecific aza-semipinacol rearrangement afforded enantioenriched indolenine derivatives bearing a C3-quaternary stereocenter via an tunable aryl/alkenyl migration. The combined steps enabled a divergent access to dearomatized indole derivatives with either a $\mathrm{C} 3-$ or a $\mathrm{C} 2-$ quaternary stereocenter.

\section{Acknowledgements}

The National Natural Science Foundation of China (Grant No. 21822304) are acknowledged for financial support. The technology platform of CBMS is acknowledged for providing instrumentation and computational resources. 
Keywords: indoles · indolenine · catalytic asymmetric dearomatization · stereospecific rearrangement · palladium catalysis

[1] For representative reviews, see: a) P. Ruiz-Sanchis, S. A. Savina, F Albericio, M. Álvarez, Chem. Eur. J. 2011, 17, 1388-1408; b) S.-M. Li, Nat. Prod. Rep. 2010, 27, 57-78.

[2] For representative reviews and examples, see: a) T. S. Silva, M. T. Rodrigues Jr, H. Santos, L. A. Zeoly, W. P. Almeida, R. C. Barcelos, R. C Gomes, F. S. Fernandes, F. Coelho, Tetrahedron 2019, 75, 2063-2097; b) J. Bariwal, L. G. Voskressensky, E. V. Van der Eycken, Chem. Soc. Rev. 2018, 47, 3831-3848; c) J. Song, D.-F. Chen, L.-Z. Gong, Natl. Sci. Rev. 2017, 4, 381-396; d) M. J. James, P. O'Brien, R. J. Taylor, W. P. Unsworth, Chem. Eur. J. 2016, 22, 2856-2881; e) J. D. Podoll, Y. Liu, L. Chang, S Walls, W. Wang, X. Wang, Proc. Natl. Acad. Sci. U. S. A. 2013, 110,1557315578; f) M. Bandini, A. Eichholzer, Angew. Chem. Int. Ed. 2009, 48, 9608 9644; Angew. Chem. 2009, 121, 9786-9824.

[3] For representative reviews, see: a) C. Zheng, S.-L. You, ACS Cent. Sci. 2021, 7, 432-444; b) Z. Wang, Org. Biomol. Chem. 2020, 18, 4354-4370 c) C. Zheng, S.-L. You, Nat. Prod. Rep. 2019, 36, 1589-1605; d) J. M. Saya E. Ruijter, R. V. A. Orru, Chem. Eur. J. 2019, 25, 8916-8935; e) J.-B. Chen Y.-X. Jia, Org. Biomol. Chem. 2017, 15, 3550-3567; f) C. Zheng, S.-L. You, Chem 2016, 1, 830-857; g) W.-T. Wu, L. Zhang, S.-L. You, Chem. Soc. Rev. 2016, 45, 1570-1580; h) S. P. Roche, J.-J. Youte Tendoung, B. Tréguier Tetrahedron 2015, 71, 3549-3591; i) C. X. Zhuo, C. Zheng, S.-L. You, Acc. Chem. Res. 2014, 47, 2558-2573; j) C. X. Zhuo, W. Zhang, S.-L. You, Angew. Chem. Int. Ed. 2012, 51, 12662-12686; Angew. Chem. 2012, 124 12834-12858; For a book, see: k) S.-L. You, Asymmetric Dearomatization Reactions, VCH, Weinheim, 2016

[4] For a review, see: a) N. Zeidan, M. Lautens, Synthesis 2019, 51, 4137 4146. For representative examples, see: b) R.-X. Liang, L.-J. Song, J.-B. Lu, W.-Y. Xu, C. Ding, Y.-X. Jia, Angew. Chem. Int. Ed. 2021, 60, 74127417; Angew. Chem. 2020, 133, 7488-7493; c) Y. Li, H.-Y. Zhang, Y. Zhang Y.-P. Han, J. Zhao, Y.-M. Liang, J. Org. Chem. 2021, 86, 14640-14651; d) Y. Li, Yue-Su, H.-Y. Zhang, Y. Zhang, Dong-Han, Y.-P. Han, J. Zhao, Y.M. Liang, ChemistrySelect 2021, 6, 4719-4724; e) M.-L. Han, W. Huang Y.-W. Liu, M. Liu, H. Xu, H. Xiong, H.-X. Dai, Org. Lett. 2021, 23, 172-177 f) D. Gao, L. Jiao, J. Org. Chem. 2021, 86, 5727-5743; g) Z. Zhang, B.-S. Zhang, K.-L. Li, Y. An, C. Liu, X.-Y. Gou, Y.-M. Liang, J. Org. Chem. 2020, 85, 7817-7839; h) C. Shen, N. Zeidan, Q. Wu, C. B. J. Breuers, R.-R. Liu, Y.-X. Jia, M. Lautens, Chem. Sci. 2019, 10, 3118-3122; i) R.-X. Liang, K. Wang, Q. Wu, W.-J. Sheng, Y.-X. Jia, Organometallics 2019, 38, $3927-$ 3930; j) R.-X. Liang, R.-Z. Yang, R.-R. Liu, Y.-X. Jia, Org. Chem. Front 2018, 5, 1840-1843; k) X. Li, B. Zhou, R.-Z. Yang, F.-M. Yang, R.-X. Liang, R.-R. Liu, Y.-X. Jia, J. Am. Chem. Soc. 2018, 140, 13945-13951; I) X. Qin M. W. Y. Lee, J. S. Zhou, Angew. Chem. Int. Ed. 2017, 56, 12723-12726
Angew. Chem. 2017, 129, 12897-12900; m) R.-R. Liu, Y.-G. Wang, Y.-L. Li, B.-B. Huang, R.-X. Liang, Y.-X. Jia, Angew. Chem. Int. Ed. 2017, 56 7475-7478; Angew. Chem. 2017, 129, 7583-7586; n) K. Douki, H. Ono, T. Taniguchi, J. Shimokawa, M. Kitamura, T. Fukuyama, J. Am. Chem. Soc 2016, 138, 14578-14581; o) C. Shen, R.-R. Liu, R.-J. Fan, Y.-L. Li, T.-F. Xu J.-R. Gao, Y.-X. Jia, J. Am. Chem. Soc. 2015, 137, 4936-4939; p) K.-J. Wu, L.-X. Dai, S.-L. You, Org. Lett. 2012, 14, 3772-3775.

[5] H. Chu, J. Cheng, J. Yang, Y.-L. Guo, J. Zhang, Angew. Chem. Int. Ed. 2020, 59, 21991-21996; Angew. Chem. 2020, 132, 22175-22180.

[6] In addition to indole, this CADA strategy could also be extended to $\mathrm{OH}$ - or $\mathrm{NH}$-containing electron-rich aromatic substrates. For selected examples see: a) X. Mu, H. Yu, H. Peng, W. Xiong, T. Wu, W. Tang, Angew. Chem. Int. Ed. 2020, 59, 8143-8147; Angew. Chem. 2020, 132, 8220-8224; b) L. Fan, J. Liu, L. Bai, Y. Wang, X. Luan, Angew. Chem. Int. Ed. 2017, 56 14257-14261; Angew. Chem. 2017, 129, 14445-14449; c) L. Bai, Y. Yuan J. Liu, J. Wu, L. Han, H. Wang, Y. Wang, X. Luan, Angew. Chem. Int. Ed. 2016, 55, 6946-6950; Angew. Chem. 2016, 128, 7060-7064; d) L. Yang, H. Zheng, L. Luo, J. Nan, J. Liu, Y. Wang, X. Luan, J. Am. Chem. Soc. 2015 137, 4876-4879; e) K. Du, P. Guo, Y. Chen, Z. Cao, Z. Wang, W. Tang Angew. Chem. Int. Ed. 2015, 54, 3033-3037; Angew. Chem. 2015, 127 3076-3080; f) R.-Q. Xu, Q. Gu, W.-T. Wu, Z.-A. Zhao, S.-L. You, J. Am Chem. Soc. 2014, 136, 15469-15472; g) S. Rousseaux, J. García-Fortanet, M. A. Del Aguila Sanchez, S. L. Buchwald, J. Am. Chem. Soc. 2011, 133 9282-9285; h) J. García-Fortanet, F. Kessler, S. L. Buchwald, J. Am. Chem Soc. 2009, 131, 6676-6677.

[7] a) G. L. Trammel, R. Kuniyil, P. F. Crook, P. Liu, M. K. Brown, J. Am. Chem Soc. 2021, 143, 16502-16511; b) P. Yang, R.-Q. Xu, C. Zheng, S.-L. You Chin. J. Chem. 2020, 38, 235-241; c) Z. Liu, J. Chen, H.-X. Lu, X. Li, Y. Gao, J. R. Coombs, M. J. Goldfogel, K. M. Engle, Angew. Chem. Int. Ed. 2019, 58, 17068-17073; Angew. Chem. 2019, 131, 17224-17229.

[8] V. Bhat, E. R. Welin, X. Guo, B. M. Stoltz, Chem. Rev. 2017, 117, 45284561.

[9] F. Ceccacci, G. Mancini, P. Mencarelli, C. Villani, Tetrahedron: Asymmetry 2003, 14, 3117-3122.

[10] a) Q. Wang, J. Hu, N. Zheng, Org. Lett. 2019, 21, 614-617; b) Y. Yu, J. Li, L. Jiang, J.-R. Zhang, L. Zu, Angew. Chem. Int. Ed. 2017, 56, 9217-9221; Angew. Chem. 2017, 129, 9345-9349; c) Y. Yu, G. Li, L. Jiang, L. Zu, Angew. Chem. Int. Ed. 2015, 54, 12627-12631; Angew. Chem. 2015, 127, 12818-12822.

[11] B. Zhou, H. Wang, Z.-Y. Cao, J.-W. Zhu, R.-X. Liang, X. Hong, Y.-X. Jia Nat. Commun. 2020, 11, 4380

[12] Deposition Number 2074943 (for 3aa), 2120649 (for 4aa'), and 2120650 (for $4 \mathbf{a m}$ ') contains the supplementary crystallographic data for this paper. These data are provided free of charge by the joint Cambridge Crystallographic Data Centre and Fachinformationszentrum Karlsruhe Access Structures service www.ccdc.cam.ac.uk/structures. 